\title{
Electrical conductivity and pH modelling of magnesium oxide-ethylene glycol nanofluids
}

\author{
MEHDI MEHRABI, MOHSEN SHARIFPUR*® and JOSUA P MEYER \\ Department of Mechanical and Aeronautical Engineering, University of Pretoria, Pretoria 0002, South Africa \\ *Author for correspondence (mohsen.sharifpur@up.ac.za)
}

MS received 23 September 2018; accepted 20 November 2018; published online 4 April 2019

\begin{abstract}
Nanofluids as new composite fluids have found their place as one of the attractive research areas. In recent years, research has increased on using nanofluids as alternative heat transfer fluids to improve the efficiency of thermal systems without increasing their size. Therefore, the examination and approval of different novel modelling techniques on nanofluid properties have made progress in this area. Stability of the nanofluids is still an important concern. Research studies on nanofluids have indicated that electrical conductivity and $\mathrm{pH}$ are two important properties that have key roles in the stability of the nanofluid. In the present work, three different sizes of magnesium oxide (MgO) nanoparticles of 20, 40 and $100 \mathrm{~nm}$ at different volume fractions up to $3 \%$ of the base fluid of ethylene glycol (EG) were studied for $\mathrm{pH}$ and electrical conductivity modelling. The temperature of the nanofluids was between 20 and $70^{\circ} \mathrm{C}$ for modelling. A genetic algorithm polynomial neural network hybrid system and an adaptive neuro-fuzzy inference system approach have been utilized to predict the $\mathrm{pH}$ and the electrical conductivity of MgO-EG nanofluids based on an experimental data set.
\end{abstract}

Keywords. Nanofluids; pH; electrical conductivity; GA-PNN; ANFIS; MgO; ethylene glycol.

\section{Introduction}

Industrial techniques and technological advancement are continually being tailored towards sustainable development. This is being witnessed in modern manufacturing techniques and devices such as microelectronics, transportation, MEMS and NEMS. The associated thermal management challenges with these new/emerging techniques and devices are very crucial and need urgent attention. In recent decades, nanofluids have been proposed for use as alternative heat transfer fluids in these devices because the conventional heat transfer fluids such as water, engine oil, ethylene glycol etc., have characteristically poor thermal properties. The use of extended surfaces is also often ruled out mainly because they increase the size of equipment. However, there are still challenges with the use of this newly formulated heat transfer fluids (nanofluids). Some of the challenges are the problem of stability, inconsistent enhancement in thermal conductivity, electrical conductivity and excessive increment of effective viscosity.

Thermal conductivity and viscosity of nanofluids have received good attention theoretically and experimentally in order to understand the underlying causes of the inconsistent enhancements [1-6]. Hong et al [7] showed that agglomeration formation is one of the underlying factors that affect the enhancement value of nanofluids. They sonicated Fe-EG nanofluids for $30 \mathrm{~min}$ (optimal sonication time) and measured the cluster size and thermal conductivity with time after ultrasonication was stopped. One hour after ultrasonication was stopped, their results signified that cluster size increased and the thermal conductivity enhancement reduced from 14.2 to 8.5\%. Xuan et al [8] and Prasher et al [9] also showed that aggregation has a pronounced effect on the behaviour of the thermal conductivity of nanofluids. On the contrary, Putnam et al [10] established that well homogenized and stably prepared nanofluids do not display any anomalous enhancement of thermal conductivity.

The theoretical model on a property (thermal conductivity) of a solid-liquid mixture was first established by Maxwell in 1873 [11], followed by Einstein for viscosity in 1906 [1]. Models have been applied to experimental data obtained from different nanofluids with an agreement for low volume concentrations $[12,13]$. Researchers have shown the lack of a hybrid model for the prediction of nanofluid properties $[11,13,14]$ which are essential to make nanofluids applicable in industries and engineering systems. The mismatches between the experimental data and models are often related to the instability of the nanofluids. Surface active agents (surfactants) or electrostatic charge induction have been proposed to ensure stable nanofluids, a situation where the van der Waals force is lower than the force of repulsion between the particles. In the case of the use of a surfactant which is a kind of chemical method, there is no standard way for adding surfactant to the nanofluid, which gives the possibility of different combinations in the formulation of nanofluids if too much surfactant added to the nanofluid. Electrostatic charging is often reported as an option of making a nanofluid stable too [15].

The stability of nanofluids has been elaborately studied in the open literature using stability markers such as visual 
observation (as the starting point), zeta potential measurement, UV-light transmittance analysis, and absorbance, turbidity and sedimentation rate [16]. A detailed explanation on the stability analysis can be found in Adio et al [16]. The $\mathrm{pH}$ of nanofluids is one of the important parameters to achieve nanoparticle stability in a suspension [17]. Most of the modelling of the properties of nanofluids in the literature is limited to thermal conductivity and viscosity of nanofluids [16,18-27], and there is a lack of modelling for other properties such as $\mathrm{pH}$ and electrical conductivities. An adaptive neuro-fuzzy inference system (ANFIS) and genetic algorithm polynomial neural networks (GA-PNN) are two novel approaches that use the advantages of neural network, fuzzy logic and genetic algorithm (GA) methods for modelling the effective $\mathrm{pH}$ and the electrical conductivity of magnesium oxide-ethylene glycol (MgO-EG) nanofluids. This was carried out to show the high capability of these two approaches to predict nanofluid electrical conductivity and pH based on an input-output experimental data set as a function of nanoparticle volume concentration, temperature and nanoparticle size.

\section{Experimental data used for the training and the testing procedure}

Adio et al [16] experimentally measured the electrical conductivity and $\mathrm{pH}$ of $\mathrm{MgO}-\mathrm{EG}$ nanofluids in temperatures ranging from 20 to $70^{\circ} \mathrm{C}$ and the volume concentrations of $0.1-2 \%$. $\mathrm{MgO}$ nanoparticles with an average particle size of 20, 40 and $100 \mathrm{~nm}$ were used in their study. Transmission electron microscopy (TEM) was used to study the $\mathrm{MgO}$ nanoparticles' morphology. The TEM images for the three different nanoparticle sizes corresponded to the manufacturer's estimations. The X-ray diffraction pattern was also obtained using an XPERT-PRO X-Ray Diffractometer, and the resulting patterns matched the Periclase structure $(\mathrm{MgO})$ from the Joint Committee on Powder Diffraction Standards (JCPDS) database. A two-step nanofluid preparation method followed by ultrasonication was used to prepare the $\mathrm{MgO}-\mathrm{EG}$ nanofluid samples.

$\mathrm{pH}$ measurement was carried out using a Jenway 3510 $\mathrm{pH}$ meter with -2 to $19.999 \mathrm{pH}$ measurement range and $0.3 \%$ measurement accuracy. The meter was calibrated using the inbuilt two-point calibration at $25^{\circ} \mathrm{C}$, and the buffer solutions corresponding to these points are 7 and 10 respectively. A CON700 electrical conductivity meter manufactured by EUTECH Instrument was used for electrical conductivity measurements. The electrical conductivity meter was calibrated with a $1413 \mu \mathrm{S} \mathrm{cm} \mathrm{cm}^{-1}$ standard calibration fluid supplied by the manufacturer at $25^{\circ} \mathrm{C}$. The temperature of the samples was maintained with the aid of a programmable thermal bath connected to a water jacket. Both meters are equipped with a slope monitor which gives a signal when the measurement does not vary in the range
0.005 and 0.01 for $\mathrm{pH}$ and the electrical conductivity meter, respectively.

Adio et al [16] measured the electrical conductivity of the base fluid, without the presence of $\mathrm{MgO}$ nanoparticles for temperatures ranging from 20 to $70^{\circ} \mathrm{C}$. The result indicated that adding $\mathrm{MgO}$ nanoparticles to the base fluid steadily increases the electrical conductivity. The electrical conductivity also showed a significant dependency on the temperature, and on increasing the temperature, the electrical conductivity increased too. They also investigated the effect of volume concentration on the electrical conductivity of nanofluids, and they reported that electrical conductivity increases with the increase in the volume fraction.

Adio et al [16] also showed that $\mathrm{pH}$ of $\mathrm{MgO}-\mathrm{EG}$ nanofluids with different volume concentrations and particle sizes follows a similar pattern with respect to increase in temperature and further ultrasonication does not affect this trend. They also showed that the temperature variation does not affect the value of $\mathrm{pH}$ of the base fluid.

\section{Proposed models for the electrical conductivity and pH of MgO-EG nanofluids}

\subsection{Proposed models by using ANFIS}

In this paper, the ANFIS approach has been implemented to model the electrical conductivity and $\mathrm{pH}$ of $\mathrm{MgO} / \mathrm{EG}$ nanofluids concerning input parameters of temperature, volume concentration and nanoparticle size. In this study, $T$ (temperature), $\phi$ (volume concentration) and $d_{\mathrm{p}}$ (nanoparticle size) are inputs and the electrical conductivity and $\mathrm{pH}$ of $\mathrm{MgO} / \mathrm{EG}$ nanofluids are the outputs of the system. Generalized bell-shaped membership functions are used for the distribution of input variables. The three inputs $\left(T, \phi, d_{\mathrm{p}}\right)$ of the fuzzy inference system are classified into two fuzzy sets each (tables 1 and 2).

Table 1. Premise parameters of the generalized bell-shaped membership function for modelling of the electrical conductivity of $\mathrm{MgO} / \mathrm{EG}$ nanofluids.

\begin{tabular}{cccc}
\hline & $a_{i}$ & $b_{i}$ & $c_{i}$ \\
\hline $\begin{array}{l}\text { Temperature }(T) \\
\text { MF1 }\end{array}$ & $\left.{ }^{\circ} \mathrm{C}\right)$ & & \\
MF2 & 24.99 & 1.543 & 20.1 \\
Volume concentration $(\phi)(\%)$ & 0.316 & 70.12 \\
MF1 & 25.06 & & \\
MF2 & 2.002 & 1.825 & 0.4353 \\
Nanoparticle size & $\left(d_{p}\right)(\mathrm{nm})$ & 1.95 & 2.69 \\
MF1 & 40 & & 20 \\
MF2 & 40 & 2.001 & 100 \\
\hline
\end{tabular}

$c_{i}$ determines the centre of the corresponding membership function; $a_{i}$ is the half width and $b_{i}$ (together with $a_{i}$ ) controls the slopes at the crossover points. 
Table 2. Premise parameters of the generalized bell-shaped membership function for modelling of the $\mathrm{pH}$ of $\mathrm{MgO} / \mathrm{EG}$ nanofluids.

\begin{tabular}{cccc}
\hline & $a_{i}$ & $b_{i}$ & $c_{i}$ \\
\hline Temperature $(T)$ & $\left({ }^{\circ} \mathrm{C}\right)$ & & \\
MF1 & 26.15 & 1.765 & 21.13 \\
MF2 & 23.04 & 4.572 & 71.65 \\
Volume concentration $(\phi)(\%)$ & & \\
MF1 & 1.068 & 3.413 & 0.6178 \\
MF2 & 0.9889 & 3.022 & 0.9571 \\
Nanoparticle size & $\left(d_{p}\right)(n m)$ & & \\
MF1 & 39.99 & 2.072 & 20 \\
MF2 & 40 & 2.013 & 100 \\
\hline
\end{tabular}

$c_{i}$ determines the centre of the corresponding membership function; $a_{i}$ is the half-width and $b_{i}$ (together with $a_{i}$ ) controls the slopes at the crossover points.

Table 3. Consequent parameters of the proposed ANFIS model for modelling of the electrical conductivity of $\mathrm{MgO} / \mathrm{EG}$ nanofluids.

\begin{tabular}{lcccc}
\hline Rule no. & $p_{i}$ & $q_{i}$ & $r_{i}$ & $c_{i}$ \\
\hline 1 & 0.009484 & 23.34 & 1.093 & 0.05487 \\
2 & -0.03289 & 1.684 & -0.02438 & 0.002173 \\
3 & 0.3196 & 22.88 & -4.208 & -0.2117 \\
4 & 0.3602 & 0.8126 & 0.3006 & -0.00632 \\
5 & 0.2117 & 34.58 & 1.015 & 0.05134 \\
6 & 0.1856 & 6.24 & -0.1924 & 0.000341 \\
7 & -0.2263 & 30.76 & -4.737 & -0.2387 \\
8 & 0.2673 & -3.355 & 0.5022 & -0.0055 \\
\hline
\end{tabular}

Table 4. Consequent parameters of the proposed ANFIS model for modelling of the $\mathrm{pH}$ of $\mathrm{MgO} / \mathrm{EG}$ nanofluids.

\begin{tabular}{lcccc}
\hline Rule no. & $p_{i}$ & $q_{i}$ & $r_{i}$ & $c_{i}$ \\
\hline 1 & -0.02644 & 0.5997 & 0.559 & 0.0279 \\
2 & -0.0139 & 2.707 & 0.05734 & 0.001863 \\
3 & -0.02617 & 0.3001 & 0.5435 & 0.02705 \\
4 & -0.02865 & -0.779 & 0.09148 & 0.002164 \\
5 & -0.01595 & 0.2321 & 0.5119 & 0.02555 \\
6 & 0.01899 & 1.557 & 0.04809 & 0.001662 \\
7 & -0.02823 & 0.046 & 0.5884 & 0.0293 \\
8 & -0.03712 & -0.3692 & 0.09157 & 0.002269 \\
\hline
\end{tabular}

A typical fuzzy rule for our proposed models is as follows:

$$
\begin{aligned}
& \text { Output ( } \mathrm{pH} \text { or Electrical conductivity) } \\
& \quad=p_{i} \cdot T_{i}+q_{i} \cdot \phi_{i}+r_{i} \cdot d_{\mathrm{p}_{i}}+c_{i}
\end{aligned}
$$

Here $p_{i}, q_{i}$ and $r_{i}$ are referred to as consequent parameters. In tables 3 and 4, these parameters are given for the proposed models. Both of our proposed models have eight fuzzy rules. During training of the ANFIS system for modelling the
Table 5. Statistical criteria used for the analysis of the results.

\begin{tabular}{lr}
\hline Statistical criterion & Equation \\
\hline Mean absolute error & MAE $=\frac{1}{n} \sum_{i=1}^{n}\left|X_{\mathrm{p}}-X_{\mathrm{a}}\right|$ \\
Mean relative error & $\mathrm{MRE}(\%)=\frac{100}{n} \sum_{i=1}^{n}\left(\frac{\left|X_{\mathrm{p}}-X_{\mathrm{a}}\right|}{X_{\mathrm{a}}}\right)$ \\
Root mean square error & $\mathrm{RMSE}=\sqrt{\frac{1}{n} \sum_{i=1}^{n}\left(X_{\mathrm{p}}-X_{\mathrm{a}}\right)^{2}}$ \\
\hline
\end{tabular}

$X_{\mathrm{p}}$ is the predicted value and $X_{\mathrm{a}}$ is the actual (experimental) data.

electrical conductivity and $\mathrm{pH}$ of $\mathrm{MgO} / \mathrm{EG}$ nanofluids, 77 sets of experimental data were used to conduct 1500 cycles of learning and 33 sets of experimental data were reserved for benchmarking. In table 5, statistical criteria that have been used for benchmarking of the proposed models are given. More information on the structure of the ANFIS network is given in Mehrabi et al [28] and Rezazadeh et al [29].

\subsection{Proposed models by using GA-PNN}

Figure 1 shows the structure of the GA-PNN hybrid system that was used for modelling of the $\mathrm{pH}$ and the electrical conductivity of $\mathrm{MgO}-\mathrm{EG}$ nanofluids. In this hybrid system, GA was applied to determine the group method of data handling (GMDH) polynomial neural network characteristics, such as network weights, bias coefficients and hidden layers in the form of chromosomes through the minimization of the training error. On the other hand, the GMDH was utilized for the learning process of the polynomial neural network. Detailed information about this hybrid system and how different parts are related to each other has been given in Mehrabi et al $[30,31]$.

The architectures of GA-PNN models for predicting the $\mathrm{pH}$ and the electrical conductivity of $\mathrm{MgO} / \mathrm{EG}$ nanofluids are shown in figure $2 \mathrm{a}$ and $\mathrm{b}$ which correspond to the genome representation of 1123122333331312 for the proposed model for the electrical conductivity and 1123222311112312 for the proposed model for the $\mathrm{pH}$ in which 1,2 and 3 stand for temperature $T\left({ }^{\circ} \mathrm{C}\right)$, volume concentration $\phi$ and nanoparticle size $d_{\mathrm{p}}(\mathrm{nm})$, respectively. The equivalent polynomial models for the electrical conductivity and $\mathrm{pH}$ based on network architecture are presented in Appendixes I and II.

\subsection{Results of the proposed models}

Figure 3 shows the comparison of the experimental data and the proposed GA-PNN and ANFIS models for the electrical conductivity of $\mathrm{MgO} / \mathrm{EG}$ nanofluids with a particle size of $20 \mathrm{~nm}$, volume concentration of $1 \%$ in the temperature range of $20-70^{\circ} \mathrm{C}$. The ANFIS model predicts the experimental data well $(\mathrm{MAE}=1.854, \mathrm{MRE}=14.88 \%$ and RMSE $=1.863)$. The proposed GA-PNN model is also wellmatched with the experimental data $(\mathrm{MAE}=1.066, \mathrm{MRE}=$ $7.87 \%$ and $\mathrm{RMSE}=1.249$ ) for lower temperatures and 


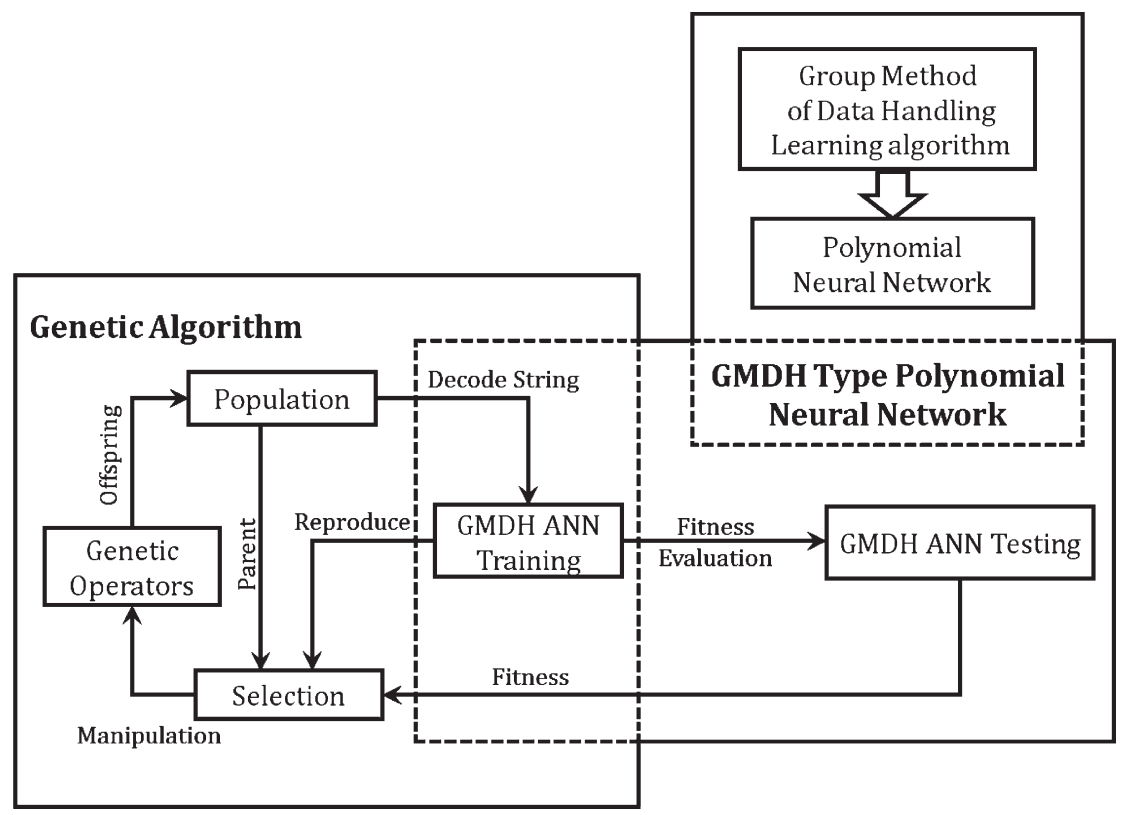

Figure 1. Combination of GA and the GMDH-type polynomial neural network approaches in a hybrid system.

Laver 1

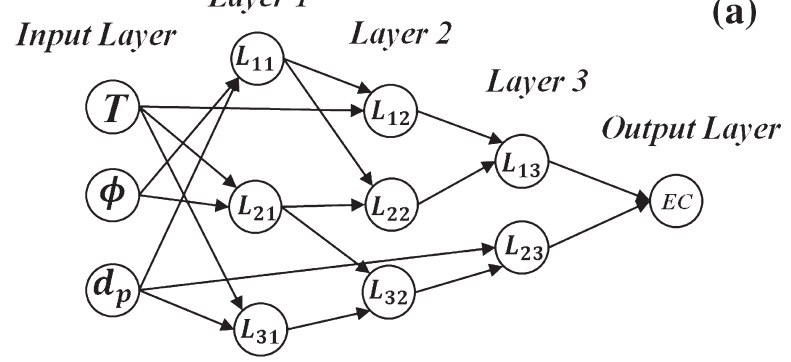

Layer 1

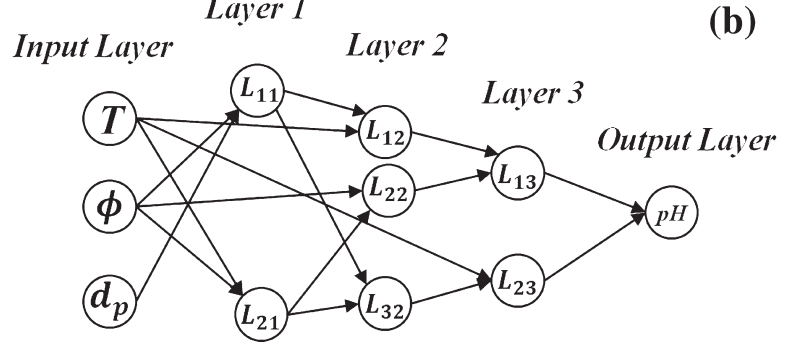

Figure 2. Structure of the GA-PNN hybrid system for (a) the electrical conductivity and (b) the $\mathrm{pH}$ of $\mathrm{MgO} / \mathrm{EG}$ nanofluids modelling.

predicts the electrical conductivity better than the ANFIS model.

In figures 4 and 5 , the experimental results of the electrical conductivity of the $\mathrm{MgO} / \mathrm{EG}$ nanofluid with a particle size of $100 \mathrm{~nm}$ and two volume concentrations of 0.5 and $2 \%$ are compared with the proposed GA-PNN and ANFIS

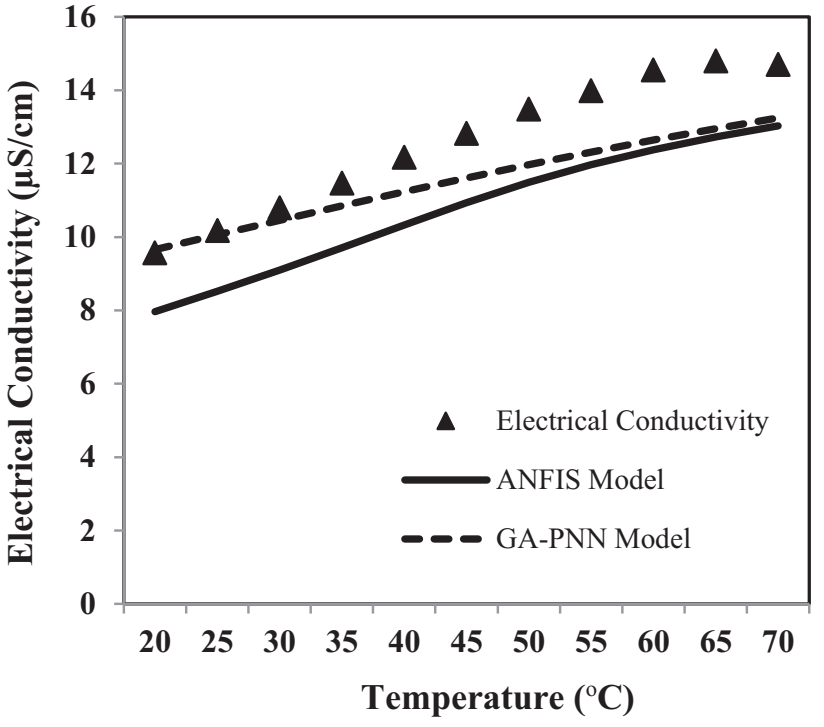

Figure 3. Comparison of the experimental data with the GAPNN and ANFIS proposed models for the electrical conductivity of $\mathrm{MgO} / \mathrm{EG}$ nanofluid ( $\mathrm{MgO} / \mathrm{EG}$ nanofluid, with an average particle size of $20 \mathrm{~nm}$ at a volume concentration of $1 \%$ ).

models. Based on the result of figure 4, the ANFIS model $(\mathrm{MAE}=1.014, \mathrm{MRE}=10.56 \%$ and $\mathrm{RMSE}=1.027)$ is in better agreement with experimental data in comparison with the GA-PNN model (MAE $=1.654$, MRE $=17.56 \%$ and RMSE = 1.693), and especially in the lower and higher temperature ranges, the ANFIS model shows a better 


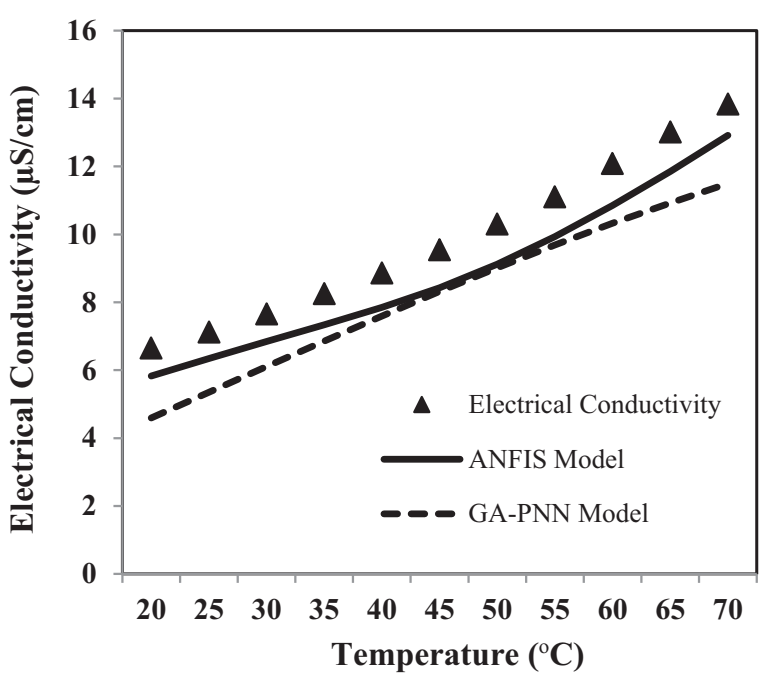

Figure 4. Comparison of the experimental data with the GAPNN and ANFIS proposed models for the electrical conductivity of $\mathrm{MgO} / \mathrm{EG}$ nanofluid (with an average particle size of $100 \mathrm{~nm}$ at a volume concentration of $0.5 \%$ ).

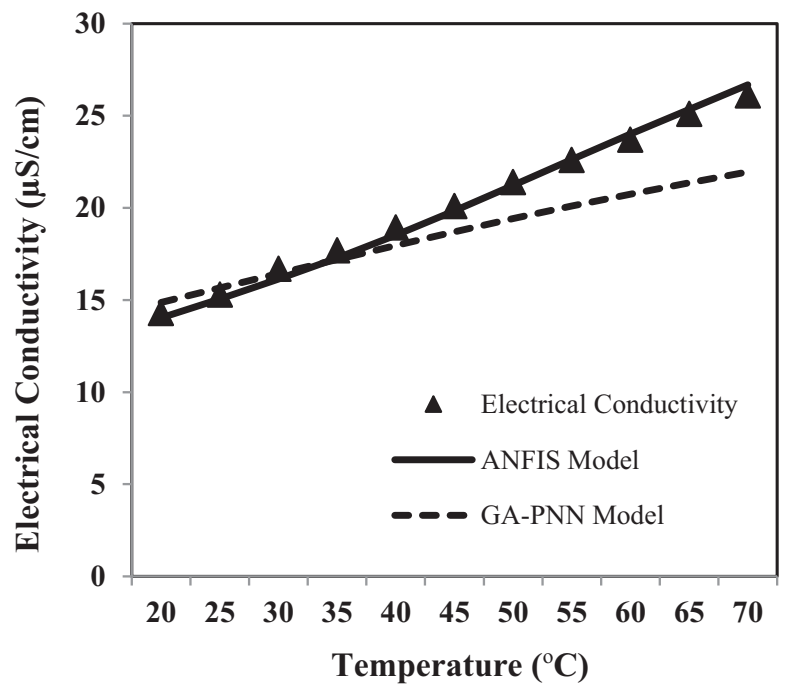

Figure 5. Comparison of the experimental data with the GAPNN and ANFIS proposed models for the electrical conductivity of $\mathrm{MgO} / \mathrm{EG}$ nanofluid (with an average particle size of $100 \mathrm{~nm}$ at a volume concentration of $2 \%$ ).

agreement. Figure 5 shows that the ANFIS model is matched well with experimental data $(\mathrm{MAE}=0.318$, MRE $=$ $1.64 \%$ and RMSE $=0.355$ ) and predicts the electrical conductivity the best. The GA-PNN proposed model is matched well with the experimental data $(\mathrm{MAE}=1.762$, $\mathrm{MRE}=7.85 \%$ and $\mathrm{RMSE}=2.209$ ) for temperatures lower than $45^{\circ} \mathrm{C}$ while becoming under-predicted for the experimental data for temperatures higher than $45^{\circ} \mathrm{C}$.

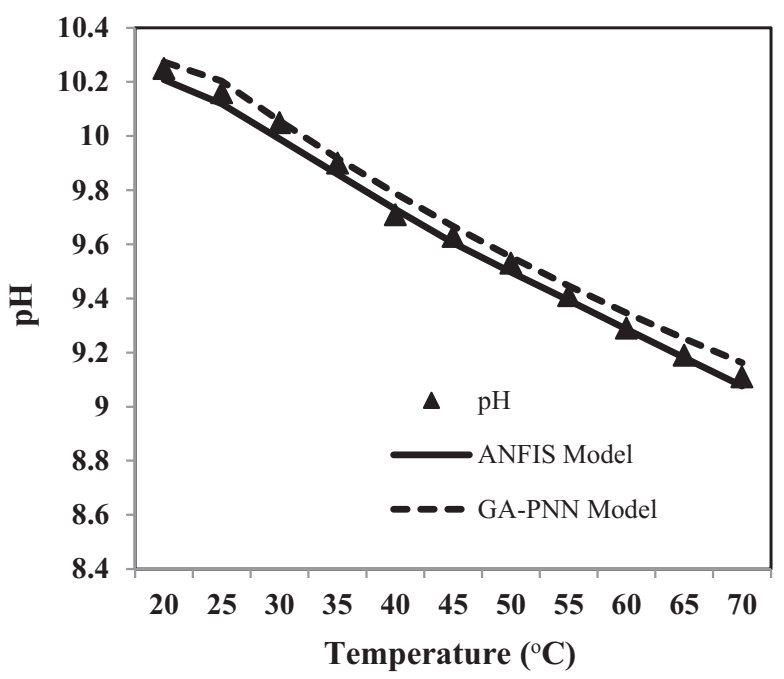

Figure 6. Comparison of the experimental data with the GA-PNN and ANFIS proposed models for the $\mathrm{pH}$ of $\mathrm{MgO} / \mathrm{EG}$ nanofluid (with an average particle size of $20 \mathrm{~nm}$ at a volume concentration of $0.5 \%$ ).

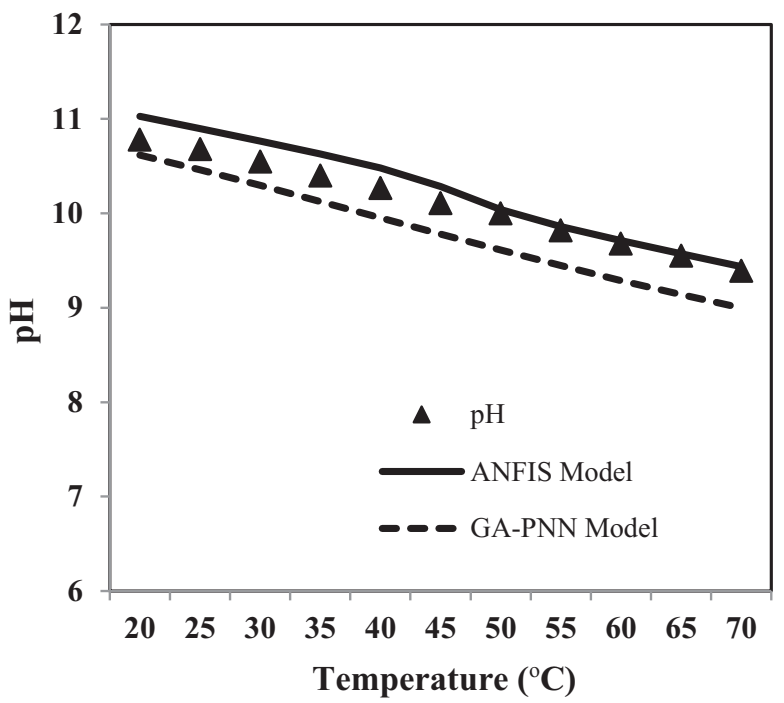

Figure 7. Comparison of the experimental data with the GA-PNN and ANFIS proposed models for the $\mathrm{pH}$ of $\mathrm{MgO} / \mathrm{EG}$ nanofluid (with an average particle size of $20 \mathrm{~nm}$ at a volume concentration of $3 \%$ ).

Figure 6 shows the experimental data of the $\mathrm{pH}$ of $\mathrm{MgO} / \mathrm{EG}$ nanofluid compared with the GA-PNN model. Also, the ANFIS proposed model for a particle size of $20 \mathrm{~nm}$ and volume concentration of $0.5 \%$ over a temperature range from 20 to $70^{\circ} \mathrm{C}$. Both the proposed models are in very good agreement with the experimental data $(\mathrm{MAE}=0.029, \mathrm{MRE}=0.29 \%$ and RMSE $=0.033$ ) for the ANFIS model and (MAE $=$ $0.039, \mathrm{MRE}=0.41 \%$ and $\mathrm{RMSE}=0.044)$ for the GAPNN proposed model. The ANFIS model predicts the $\mathrm{pH}$ 


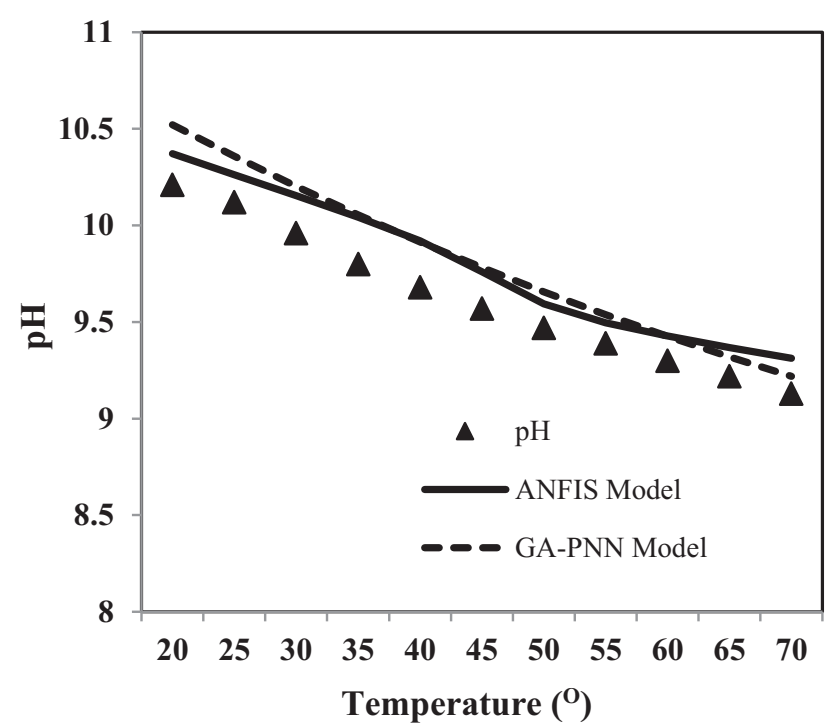

Figure 8. Comparison of the experimental data with the GA-PNN and ANFIS proposed models for the $\mathrm{pH}$ of $\mathrm{MgO} / \mathrm{EG}$ nanofluid (with an average particle size of $100 \mathrm{~nm}$ at a volume concentration of $1 \%$ ).

slightly better than the GA-PNN model, and for the higher temperatures, the ANFIS model output is exactly the same as experimental results.

In figure 7, the experimental results are compared with those of the GA-PNN model and the ANFIS model for the $\mathrm{pH}$ of $\mathrm{MgO} / \mathrm{EG}$ nanofluid with a particle size of $20 \mathrm{~nm}$, and a volume concentration of $3 \%$ and temperature ranging from 20 to $70^{\circ} \mathrm{C}$. The ANFIS model $(\mathrm{MAE}=0.134, \mathrm{MRE}=1.29 \%$ and RMSE $=0.162$ ) predicts $\mathrm{pH}$ the best when compared with the outputs of the proposed GA-PNN model (MAE = $0.319, \mathrm{MRE}=3.19 \%$ and $\mathrm{RMSE}=0.329)$. While the ANFIS model shows a better agreement, the GA-PNN model shows a very good accuracy as well.

Figure 8 shows the outputs of the ANFIS and GA-PNN models for the $\mathrm{pH}$ of $\mathrm{MgO} / \mathrm{EG}$ nanofluid compared with experimental results for a particle size of $100 \mathrm{~nm}$ and volume concentration of $1 \%$. For temperature ranging from 30 to $60^{\circ} \mathrm{C}$, both the proposed models show the same level of agreement with experimental data while for temperatures lower than $30^{\circ} \mathrm{C}$, the ANFIS model $(\mathrm{MAE}=0.164, \mathrm{MRE}=$ $1.75 \%$ and RMSE $=0.174$ ) predicts the $\mathrm{pH}$ better. The GAPNN model $(\mathrm{MAE}=0.145, \mathrm{MRE}=2.0 \%$ and $\mathrm{RMSE}=$ 0.206 ) has a better performance for temperatures higher than $60^{\circ} \mathrm{C}$.

\section{Conclusions}

Electrical conductivity and $\mathrm{pH}$ behaviour of $\mathrm{MgO}-\mathrm{EG}$ nanofluids have been investigated with respect to temperature variation, nanoparticles size, sonication time and volume fraction. The experimental results indicated that the electrical conductivity of the nanofluid samples increased significantly with the increase in temperature and volume fraction. However, concerning volume fraction, the electrical conductivity does not follow a simple linear fit which suggests counterion condensation. There is no direct relationship between the $\mathrm{MgO}$ nanoparticle size and electrical conductivity; the same trends were obtained from two different ultrasonication times investigated with no significant decrease or increase in electrical conductivity values. Regarding the $\mathrm{pH}$ of the $\mathrm{MgO}-\mathrm{EG}$ nanofluids, it reduces with the increase in temperature and is not significantly affected by the ultrasonication time except at $2 \%$ volume fraction. The relative $\mathrm{pH}$ plots buttress the fact that size of $\mathrm{MgO}$ nanoparticles does not have a direct relationship with the $\mathrm{pH}$ values and an increase in volume fraction shows an increase in $\mathrm{pH}$ up to the point where the counterion condensation effect was observed to have set in. The significance of the temperature variation in the $\mathrm{pH}$ of these nanofluids will be in its effect on the zeta potential. Summarily, $\mathrm{pH}$ and electrical conductivity are interrelated, and with the above findings, it is important to note that temperature stable nanofluids could be engineered. This can be achieved by studying the zeta potential of the nanofluids at the $\mathrm{pH}$ values as measured in the temperature regime investigated. Then the temperature corresponding to the $\mathrm{pH}$ value that gives the best zeta potential or has zeta potential more than $\pm 30 \mathrm{mV}$ (minimum threshold) may represent the temperature at which the nanofluids should be kept for all-time stability.

This study showed the successful application of two GAPNN and ANFIS approaches for the modelling of the $\mathrm{pH}$ and the electrical conductivity of $\mathrm{MgO}-\mathrm{EG}$ nanofluids as a function of various variables (volume concentration, temperature and nanoparticle size). The results showed that the GA-PNN and the ANFIS methods are accurate and effective.

\section{Appendix I}

$$
\begin{aligned}
L_{11}= & a_{1,0}+a_{1,1} \cdot \phi+a_{1,2} \cdot d_{\mathrm{p}}+a_{1,3} \cdot \phi \cdot d_{\mathrm{p}} \\
& +a_{1,4} \cdot \phi^{2}+a_{1,5} \cdot d_{\mathrm{p}}^{2} \\
L_{21}= & a_{2,0}+a_{2,1} \cdot T+a_{2,2} \cdot \phi+a_{2,3} \cdot d_{\mathrm{p}} \cdot T \\
& +a_{2,4} \cdot T^{2}+a_{2,5} \cdot \phi^{2} \\
L_{31}= & a_{3,0}+a_{3,1} \cdot T+a_{3,2} \cdot d_{\mathrm{p}}+a_{3,3} \cdot T \cdot d_{\mathrm{p}} \\
& +a_{3,4} \cdot T^{2}+a_{3,5} \cdot d_{\mathrm{p}}^{2} \\
L_{12}= & a_{4,0}+a_{4,1} \cdot T+a_{4,2} \cdot L_{11}+a_{4,3} \cdot T \cdot L_{11} \\
& +a_{4,4} \cdot T^{2}+a_{4,5} \cdot L_{11}^{2} \\
L_{22}= & a_{5,0}+a_{5,1} \cdot L_{21}+a_{5,2} \cdot L_{11}+a_{5,3} \cdot L_{21} \cdot L_{11} \\
& +a_{5,4} \cdot L_{21}^{2}+a_{5,5} \cdot L_{11}^{2} \\
L_{32}= & a_{6,0}+a_{6,1} \cdot L_{31}+a_{6,2} \cdot L_{21}+a_{6,3} \cdot L_{31} \cdot L_{21} \\
& +a_{6,4} \cdot L_{31}^{2}+a_{6,5} \cdot L_{21}^{2} \\
L_{13}= & a_{7,0}+a_{7,1} \cdot L_{12}+a_{7,2} \cdot L_{22}+a_{7,3} \cdot L_{12} \cdot L_{22} \\
& +a_{7,4} \cdot L_{12}^{2}+a_{7,5} \cdot L_{22}^{2}
\end{aligned}
$$




$$
\begin{aligned}
L_{23}= & a_{8,0}+a_{8,1} \cdot d_{\mathrm{p}}+a_{8,2} \cdot L_{32}+a_{8,3} \cdot d_{\mathrm{p}} \cdot L_{32} \\
& +a_{8,4} \cdot d_{\mathrm{p}}^{2}+a_{8,5} \cdot L_{32}^{2} \\
\mathrm{EC}= & a_{9,0}+a_{9,1} \cdot L_{13}+a_{9,2} \cdot L_{23}+a_{9,3} \cdot L_{13} \cdot L_{23} \\
& +a_{9,4} \cdot L_{13}^{2}+a_{9,5} \cdot L_{23}^{2}
\end{aligned}
$$

$L_{i j}$ is the $i$-th output in the $j$-th layer for the GA-PNN model.

$$
\begin{aligned}
& {\left[a_{i, j}\right]} \\
& \begin{array}{lllllll}
0.027747876 & 3.822604153 & 0.462429558 & -0.374659514 & -0.004205517 & 0.045114086
\end{array} \\
& \begin{array}{lllllll}
0.751137821 & 0.145938521 & 5.011703576 & -0.000502634 & -0.103220539 & 0.003901322
\end{array} \\
& \begin{array}{lllllll}
0.015971668 & 0.235979845 & 0.266171545 & -0.001501415 & -0.002750727 & 0.001161073
\end{array} \\
& \begin{array}{lllllll}
-3.283067536 & 0.095068789 & 0.819407225 & -0.000315974 & -0.000331478 & 0.003277455
\end{array} \\
& =\begin{array}{lllllll}
1.389849061 & 0.64959239 & 0.116319437 & -0.125388437 & -0.097872314 & 0.235336051
\end{array} \\
& \begin{array}{lllllll}
1.193873934 & -0.25706559 & 0.982727589 & 0.012610029 & -0.000454244 & 0.00173388
\end{array} \\
& \begin{array}{llllll}
1.105115316 & 1.489550714 & -0.683855075 & -0.098269034 & -0.027494652 & 0.133113803
\end{array} \\
& \begin{array}{lllllll}
0.010619241 & 0.176968505 & 0.67971365 & -0.002261029 & -0.005051182 & 0.008740201
\end{array} \\
& \begin{array}{lllllll}
0.028571409 & 1.176834459 & -0.191474172 & 0.057362616 & 0.072612493 & -0.129341963
\end{array}
\end{aligned}
$$

\section{Appendix II}

$$
\begin{aligned}
L_{11}= & a_{1,0}+a_{1,1} \cdot \phi+a_{1,2} \cdot d_{\mathrm{p}}+a_{1,3} \cdot \phi \cdot d_{\mathrm{p}} \\
& +a_{1,4} \cdot \phi^{2}+a_{1,5} \cdot d_{\mathrm{p}}^{2} \\
L_{21}= & a_{2,0}+a_{2,1} \cdot T+a_{2,2} \cdot \phi+a_{2,3} \cdot d_{\mathrm{p}} \cdot T \\
& +a_{2,4} \cdot T^{2}+a_{2,5} \cdot \phi^{2} \\
L_{12}= & a_{3,0}+a_{3,1} \cdot T+a_{3,2} \cdot d_{\mathrm{p}}+a_{3,3} \cdot T \cdot d_{\mathrm{p}} \\
& +a_{3,4} \cdot T^{2}+a_{3,5} \cdot d_{\mathrm{p}}^{2} \\
L_{22}= & a_{4,0}+a_{4,1} \cdot T+a_{4,2} \cdot L_{11}+a_{4,3} \cdot T \cdot L_{11} \\
& +a_{4,4} \cdot T^{2}+a_{4,5} \cdot L_{11}^{2} \\
L_{32}= & a_{5,0}+a_{5,1} \cdot L_{21}+a_{5,2} \cdot L_{11}+a_{5,3} \cdot L_{21} \cdot L_{11} \\
& +a_{5,4} \cdot L_{21}^{2}+a_{5,5} \cdot L_{11}^{2} \\
L_{13}= & a_{6,0}+a_{6,1} \cdot L_{31}+a_{6,2} \cdot L_{21}+a_{6,3} \cdot L_{31} \cdot L_{21} \\
& +a_{6,4} \cdot L_{31}^{2}+a_{6,5} \cdot L_{21}^{2} \\
L_{23}= & a_{7,0}+a_{7,1} \cdot L_{12}+a_{7,2} \cdot L_{22}+a_{7,3} \cdot L_{12} \cdot L_{22} \\
& +a_{7,4} \cdot L_{12}^{2}+a_{7,5} \cdot L_{22}^{2} \\
p H= & a_{8,0}+a_{8,1} \cdot d_{\mathrm{p}}+a_{8,2} \cdot L_{32}+a_{8,3} \cdot d_{\mathrm{p}} \cdot L_{32} \\
& +a_{8,4} \cdot d_{\mathrm{p}}^{2}+a_{8,5} \cdot L_{32}^{2}
\end{aligned}
$$

$L_{i j}$ is the $i$-th output in the $j$-th layer for the GA-PNN model.

$$
\begin{aligned}
& {\left[a_{i, j}\right]} \\
& \begin{array}{llllll}
0.033444754 & 0.57742064 & 0.557373458 & -0.096976696 & -0.004692827 & 0.000620553
\end{array} \\
& \begin{array}{llllll}
9.898066327 & -0.023691553 & 1.141784359 & 0.0000969 & -0.210843577 & -0.005661005
\end{array} \\
& \begin{array}{llllll}
-44.23417905 & 0.112053455 & 10.03507958 & 0.0000876 & -0.447629593 & -0.01478803
\end{array} \\
& \begin{array}{llllll}
134.3682947 & 11.80598176 & -28.47847853 & 0.200363275 & 1.615464421 & -1.281415173
\end{array} \\
& =\begin{array}{llllll}
-42.30134392 & 12.29220823 & -2.444815909 & -0.732689135 & 0.070198963 & 0.200862777
\end{array} \\
& \begin{array}{lllllll}
-1.052141722 & 2.065814262 & -0.846199307 & -0.042050653 & 0.055096649 & -0.024438988
\end{array} \\
& \begin{array}{llllll}
-74.54960615 & 0.253862617 & 15.70866275 & -0.000155682 & -0.718791861 & -0.026399959
\end{array} \\
& \begin{array}{llllll}
0.404458237 & -2.519092266 & 3.422661793 & 2.167188004 & 1.817553076 & -3.979307098
\end{array}
\end{aligned}
$$




\section{References}

[1] Einstein A 1906 Ann. Phys.-Berlin 437

[2] Hatschek E 1913 Trans. Faraday Soc. 980

[3] Brinkman H C 1952 J. Chem. Phys. 20571

[4] Awua J T, Ibrahim J S, Adio S A, Mehrabi M, Sharifpur M and Meyer J P 2018 Bull. Mater. Sci. 41156

[5] Hong T, Yang H and Choi C J 2005 J. Appl. Phys. 97064311

[6] Assael M J, Metaxa I N, Kakosimos K and Constantinou D 2006 Int. J. Thermophys. 27999

[7] Hong K S, Hong T and Yang H 2006 Appl. Phys. Lett. 88 031901

[8] Xuan Y, Li Q and Hu W 2003 AIChE J. 491038

[9] Prasher R, Evans W, Meakin P, Fish J, Phelan P and Keblinski P 2006 Appl. Phys. Lett. 89143119

[10] Putnam S A, Cahill D G, Braun P V, Ge Z and Shimmin R G 2006 J. Appl. Phys. 99084308

[11] Aybar H S, Sharifpur M, Azizian M R, Mehrabi M and Meyer J P 2015 Heat Transfer Eng. 361085

[12] Sharifpur M, Solomon A B, Ottermann T L and Meyer J P 2018 Int. Commun. Heat Mass 98297

[13] Nwosua Paul N, Meyer J P and Sharifpur M 2014 Comput. Fluids 101241

[14] Sharifpur M, Yousefi S and Meyer J P 2016 Int. Commun. Heat Mass 78168

[15] Adio S A, Sharifpur M and Meyer J P 2015 Heat Transfer Eng. 361241

[16] Adio S A, Sharifpur M and Meyer J P 2015 Bull. Mater. Sci. 381345

[17] Samal S, Satpati B and Chaira D 2010 J. Alloys Compd. 504 389
[18] Sharifpur M, Ntumba T, Meyer J P and Manca O 2017 Int. Commun. Heat Mass $\mathbf{8 5} 12$

[19] Adio S A, Mehrabi M, Sharifpur M and Meyer J P 2016 Int. Commun. Heat Mass 7271

[20] Ntumba T, Sharifpur M and Meyer J P 2016 Heat Transfer Eng. 371

[21] Adio S A, Sharifpur M and Meyer J P 2016 J. Exp. Nanosci. 11630

[22] Sharifpur M, Adio S A and Meyer J P 2015 Int. Commun. Heat Mass 68208

[23] Chari V D, Sharma D V S G K, Prasad P S R and Murthy S R 2013 Bull. Mater. Sci. 36517

[24] Hemmat Esfe M, Saedodin S, Bahiraei M, Toghraie D, Mahian $\mathrm{O}$ and Wongwises S 2014 J. Therm. Anal. Calorim. 118 287

[25] Hemmat Esfe M, Bahiraei M and Mahian O 2018 Powder Technol. 338383

[26] Amani M, Amani P, Kasaeian A, Mahian O, Pop I and Wongwises S 2017 Sci. Rep.-UK 717369

[27] Amani M, Amani P, Mahian O and Estellé P 2017 J. Clean Prod. 166350

[28] Mehrabi M, Pesteei S M and Pashaee T 2011 Int. Commun. Heat Mass 38525

[29] Rezazadeh S, Mehrabi M, Pesteei S M and Mirzaee I $2012 \mathrm{~J}$. Mech. Sci. Technol. 263701

[30] Mehrabi M, Rezazadeh S, Sharifpur M and Meyer J P 2012 ASME 6th International conference on energy sustainability and 10th fuel cell science, Engineering \& Technology Conference (San Diego, CA)

[31] Mehrabi M, Sharifpur M and Meyer J P 2012 Int. Commun. Heat Mass 39971 